\title{
Electrical Resistivity Monitoring of the Drift Scale Test in Yucca Mountain
}

\author{
Abelardo Ramirez \\ William Daily
}

January 13, 1997

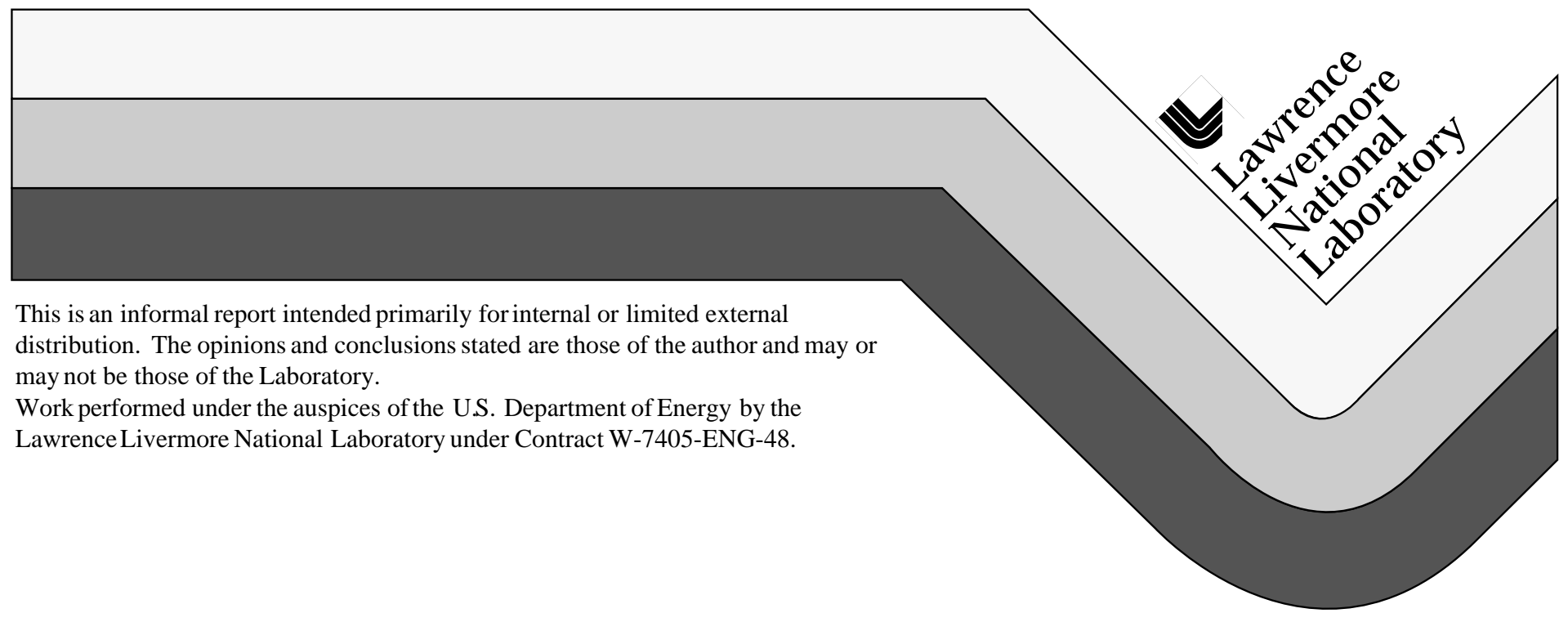




\section{DISCLAIMER}

This document was prepared as an account of work sponsored by an agency of the United States Government. Neither the United States Government nor the University of California nor any of their employees, makes any warranty, express or implied, or assumes any legal liability or responsibility for the accuracy, completeness, or usefulness of any information, apparatus, product, or process disclosed, or represents that its use would not infringe privately owned rights. Reference herein to any specific commercial product, process, or service by trade name, trademark, manufacturer, or otherwise, does not necessarily constitute or imply its endorsement, recommendation, or favoring by the United States Government or the University of California. The views and opinions of authors expressed herein do not necessarily state or reflect those of the United States Government or the University of California, and shall not be used for advertising or product endorsement purposes.

This report has been reproduced directly from the best available copy.

Available to DOE and DOE contractors from the Office of Scientific and Technical Information P.O. Box 62, Oak Ridge, TN 37831

Prices available from (423) 576-8401

Available to the public from the National Technical Information Service

U.S. Department of Commerce 5285 Port Royal Rd. Springfield, VA 22161 


\title{
Electrical Resistivity \\ Monitoring of the Drift Scale Test \\ in Yucca Mountain
}

\author{
A. Ramirez, W. Daily \\ Lawrence Livermore National Laboratory
}

\begin{abstract}
Of the several thermal, mechanical and hydrological measurements being used to monitor the rockmass response, electrical resistance tomography (ERT) is being used to monitor the movement of liquid water with a special interest in the movement of condensate out of the system. Eight boreholes, containing a total of 140 ERT electrodes, were drilled above and below the Heated Drift (HD) to form vertical planes parallel to the drift. In addition, 4 boreholes, containing 60 electrodes, drilled from the Access Observation Drift (AOD)form vertical planes at right angles to the HD. Four ERT surveys, three before and one after heating began, were conducted during the first quarter of FY 98. Tomographic images of absolute electrical resistivity have been calculated using these data and are presented in this report. The report also presents the coordinates of the electrodes used for the ERT surveys. Future reports will include images of electrical resistivity change calculated using data collected before and during the heating episode. The changes to be recovered will then be used in combination with temperature maps of the region to calculate maps of saturation change around the HD.
\end{abstract}

\section{Introduction:}

The Drift Scale test (DST) is one of the in situ thermal tests being conducted in the exploratory studies facility (ESF) in Yucca Mountain to enhance the understanding of the coupled processes. The primary objective of the DST is to investigate the thermalmechanical responses of the Topopah Spring tuff in Yucca Mountain.

This paper describes electrical resistance tomography (ERT) surveys made during the DST in order to map the changes in moisture content caused by temperature changes. Of particular interest, is the formation and movement of condensate within the fractured rock mass.

The DST is located off the Observation Drift about $40 \mathrm{~m}$ from the Main Tunnel of the ESF and about $2.8 \mathrm{~km}$ from the portal of the Tunnel. As shown in Figures 1 and 2, twelve boreholes were drilled form the HD and the AOD and electrodes emplaced. A total of 200 electrodes distributed among the 12 holes are used to conduct ERT surveys around the HD. 


\begin{tabular}{|c|c|c|c|c|c|c|c|c|c|c|}
\hline \multicolumn{11}{|c|}{ ELECTRODE COORDINATES (m) } \\
\hline \begin{tabular}{|l|} 
hole \\
name
\end{tabular} & $\begin{array}{l}\text { Hole } \\
\#\end{array}$ & $\begin{array}{l}\text { total } \\
\text { depth } \\
(\mathrm{m})\end{array}$ & \begin{tabular}{|l|} 
bottom \\
elec. \\
depth \\
$(\mathrm{m})$ \\
\end{tabular} & $\begin{array}{l}\text { collar } \\
\text { elec } \\
\text { depth } \\
(\mathrm{m}) \\
\end{array}$ & collar $\mathrm{x}$ & collar y & collar z & bottom $\mathrm{x}$ & bottom y & bottom z \\
\hline \begin{tabular}{|l|}
$A O D 1$ \\
top
\end{tabular} & 45 & 39.84 & 39.116 & 11.116 & -18.09 & 4.61 & 6.79 & 9.09 & 4.68 & 13.51 \\
\hline & & & & & & & & & & \\
\hline \begin{tabular}{|l|} 
AOD 1 \\
bott \\
\end{tabular} & 46 & 39.80 & 39.014 & 11.014 & -17.31 & 4.56 & -2.86 & 8.37 & 4.53 & -14.02 \\
\hline $\begin{array}{l}\text { AOD 5 } \\
\text { top }\end{array}$ & 62 & 40.24 & 39.014 & 11.014 & -18.39 & 24.74 & 8.22 & 9.18 & 24.84 & 13.07 \\
\hline & & & & & & & & & & \\
\hline \begin{tabular}{|l|} 
AOD 5 \\
bott. \\
\end{tabular} & 63 & 39.93 & 39.014 & 11.014 & -19.27 & 24.83 & 0.13 & 6.17 & 25.19 & -11.55 \\
\hline & & & & & & & & & & \\
\hline $\begin{array}{l}\text { HD 1 } \\
\text { top } \\
\end{array}$ & 135 & 20.00 & 19.84 & 0.84 & -0.77 & 2.71 & 3.24 & -0.96 & 2.76 & 22.24 \\
\hline \begin{tabular}{|l|} 
HD 1 \\
bott.
\end{tabular} & 136 & 16.33 & 15.774 & 1.774 & -0.75 & 2.73 & -3.39 & -0.71 & 2.63 & -17.39 \\
\hline $\begin{array}{l}\text { HD 2 } \\
\text { top }\end{array}$ & 145 & 20.09 & 18.737 & 0.737 & -0.77 & 11.89 & 3.32 & -0.89 & 12.01 & 21.32 \\
\hline \begin{tabular}{|l|}
$\mathrm{HD} 2$ \\
bott.
\end{tabular} & 146 & 16.46 & 15.797 & 1.797 & -0.79 & 11.89 & -3.41 & -1.06 & 11.92 & -17.40 \\
\hline & & & & & & & & & & \\
\hline \begin{tabular}{|l|}
$\mathrm{HD} 6$ \\
top \\
\end{tabular} & 166 & 19.82 & 19.659 & 0.659 & -0.73 & 22.86 & 3.23 & -0.56 & 23.02 & 22.23 \\
\hline \begin{tabular}{|l|} 
HD 6 \\
bott.
\end{tabular} & 167 & 15.88 & 15.748 & 1.748 & -0.74 & 22.80 & -3.39 & -0.46 & 22.75 & -17.38 \\
\hline \begin{tabular}{|l|} 
HD 8 \\
top \\
\end{tabular} & 176 & 20.00 & 19.66 & 0.66 & -0.75 & 39.29 & 3.12 & -0.78 & 39.12 & 22.12 \\
\hline $\begin{array}{l}\text { HD } 8 \\
\text { bott. }\end{array}$ & 177 & 16.20 & 15.748 & 1.748 & -0.74 & 39.32 & -3.37 & -0.75 & 39.26 & -17.37 \\
\hline
\end{tabular}

Table 1. Coordinates (in meters) for the deepest and shallowest electrodes in each ERT borehole. The coordinates for other electrodes in a borehole are obtained by linear interpolation. The assumption that the boreholes are straight provides sufficiently accurate electrode locations for the purpose of ERT data processing. The origin of the coordinate system is located along the centerline of the Heated Drift by the hot side of the bulkhead, at the springline elevation. 


\section{Electrical Resistance Tomography:}

Electrical resistance tomography (ERT) is a geophysical imaging technique which can be used to map subsurface resistivity. Rock mass heating creates temperature and liquid saturation changes which result in electrical resistivity changes that are readily measured. The ERT measurements consist of a series of voltage and current measurements from buried electrodes using an automated data collection system. The data are then processed to produce electrical resistivity tomographs using state of the art data inversion algorithms. We use these measurements to calculate tomographs that show the spatial distribution of the subsurface resistivities.

Here we describe briefly some of the important features of the two dimensional (2D) algorithm. For additional details, the reader is referred to Morelli and LaBrecque (1996). The algorithm solves both the forward and inverse problems. The forward problem is solved using a finite element technique in 2D. The inverse problem implements a regularized solution which minimizes an objective function. The objective of the inverse routine is to minimize the misfit between the forward modeling data and the field data, and a stabilizing functional of the parameters. The stabilizing functional is the solution's roughness. This means that the inverse procedure tries to find the smoothest resistivity model which fits the field data to a prescribed tolerance. Resistivity values assigned in this way to the finite element mesh constitute the ERT image. Although the mesh is of a large region around the electrode arrays, only the region inside the ERT electrode array is shown in the results because the region outside the array is poorly constrained by the data. 


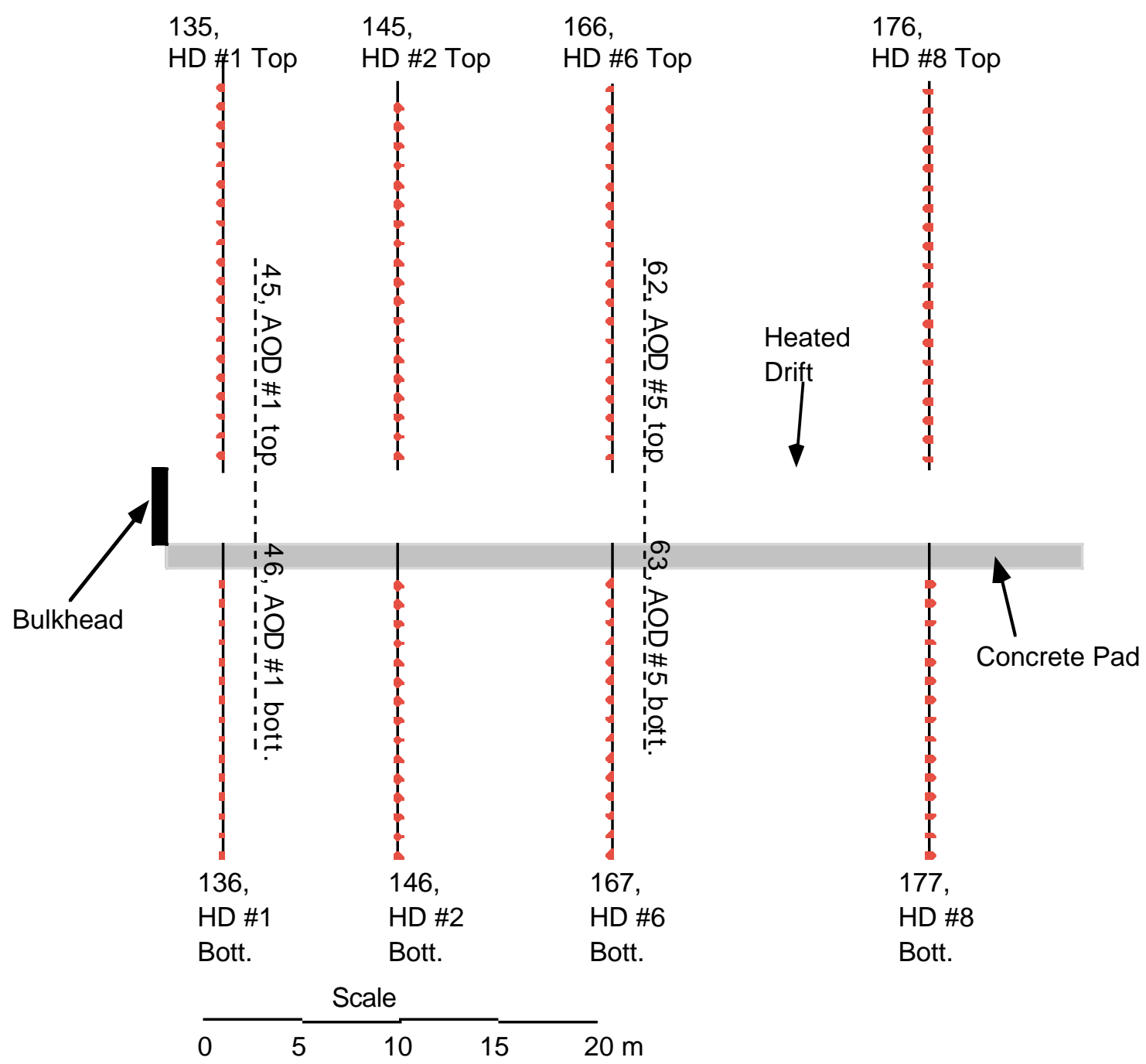

Figure 1. Cross section parallel to the HD showing the location of ERT boreholes. Boreholes drilled from the from the HD are shown as solid lines extending above and below the HD. The location of the electrodes within each borehole is shown by the small circles. The location of boreholes drilled from the AOD is shown by dashed lines. The electrode spacing for the boreholes drilled from the HD is 1 meter. 

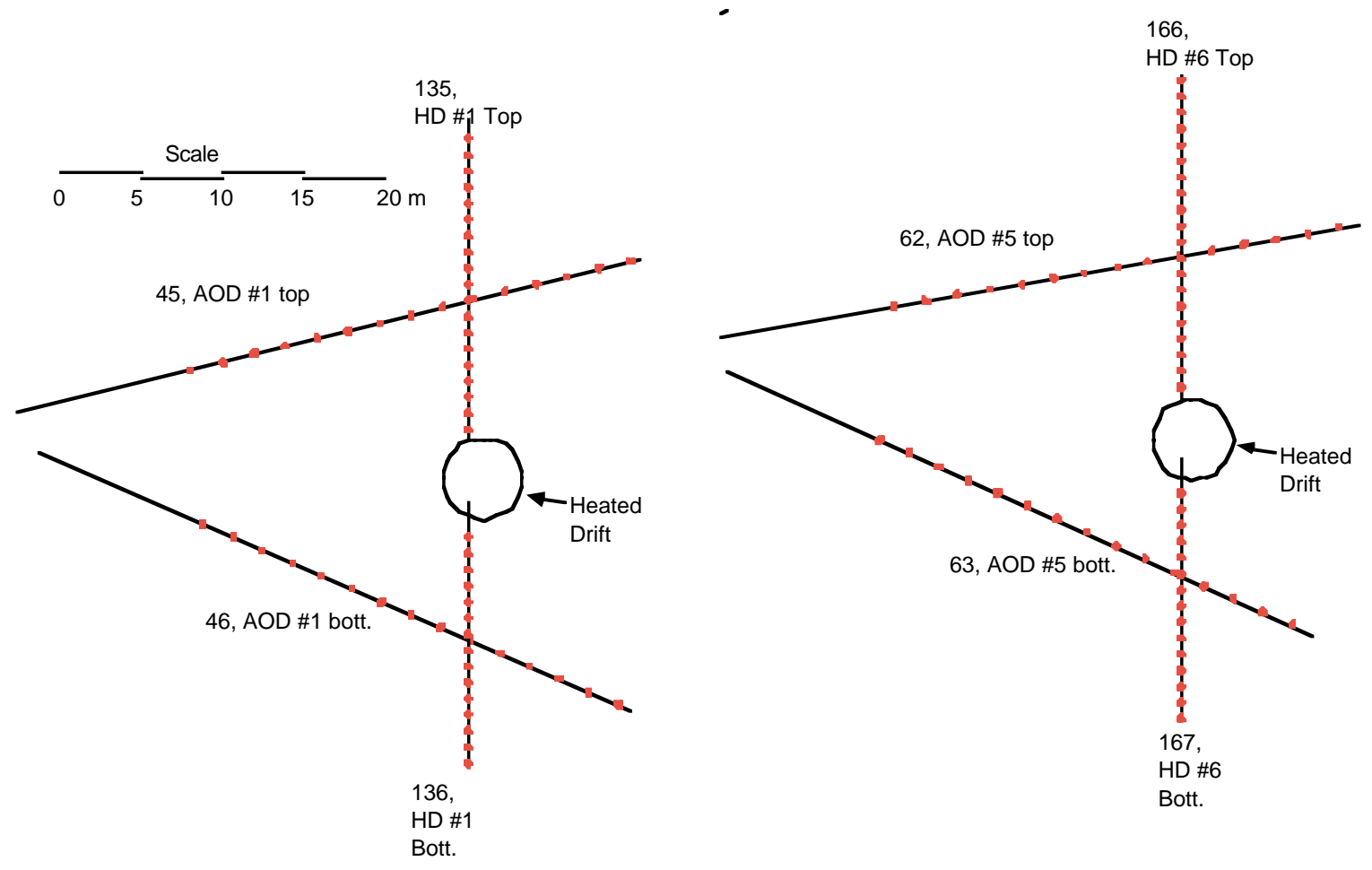

Figure 2. Two cross sections orthogonal to the HD showing the location of ERT boreholes drilled from the AOD and selected boreholes drilled from the HD. The location of the electrodes within each borehole is shown by the small circles. The electrode spacing is 1 meter for the boreholes drilled from the HD and $2 \mathrm{~m}$ for the boreholes drilled from the AOD.

\section{Description of ERT surveys:}

Along the HD, ERT survey data were collected between adjacent pairs of boreholes. For example, surveys collected below the Heated Drift are collected between boreholes 136 146, 146 - 167, and 167-177. A similar approach is used for surveys collected above the HD. These surveys provide information along two vertical planes (one above and one below the HD) which run parallel to the HD.

The surveys performed from boreholes drilled from the AOD provide information along two vertical planes which run orthogonal to the HD. These surveys are performed by combining electrodes in AOD boreholes with electrodes in HD boreholes. Figure 3 shows the location of the electrodes used for these surveys. We take advantage of the fact that HD boreholes 135 and 136 are close to AOD boreholes 45 and 46; similar comments apply to both $A O D$ boreholes 62 and 63 , and HD boreholes 166 and 167 . For these surveys, the shallowest (closest to the AOD) 10 electrodes in AOD boreholes 45 and 46 were used in combination with the shallowest 5 electrodes (to the HD) in HD boreholes 135 and 136 as shown in Figure 3. This approach provides better sensitivity and resolution of the rockmass on the left flank of the HD relative to the sensitivity and resolution which would result if only electrodes in the AOD boreholes were used.

\section{Electrode conditions:}

The working condition of the electrodes was evaluated prior to baseline data collection. A series of specialized test surveys were performed to identify typical problems with electrodes grouted in place. Problems which can be identified by these surveys include: 
a) poor electrical contact between electrode and the rock, b) continuity of wires to the electrodes, c) wire assumed to connect to one electrode was inadvertently connected to a different electrode, and d) abrasion of wire insulation creating unintended electrodes within a borehole.

The test surveys revealed that of a total of 200 electrodes installed, 193 are in good working order. The following problem electrodes were identified: 1) in borehole (HD \#2 top), the electrode closest to the collar was disconnected because borehole conditions prevented the ERT electrode array to be pushed to its intended depth, 2) the four deepest (farthest away from the collar) electrodes in (HD \#8 top) were disconnected; the root cause of this problem is unknown, 3) along (AOD \#1), the third electrode from the collar provided incorrect data due to unknown conditions, and, 4) along borehole (AOD \#5), the fourth electrode from the collar provided incorrect data due to unknown conditions.

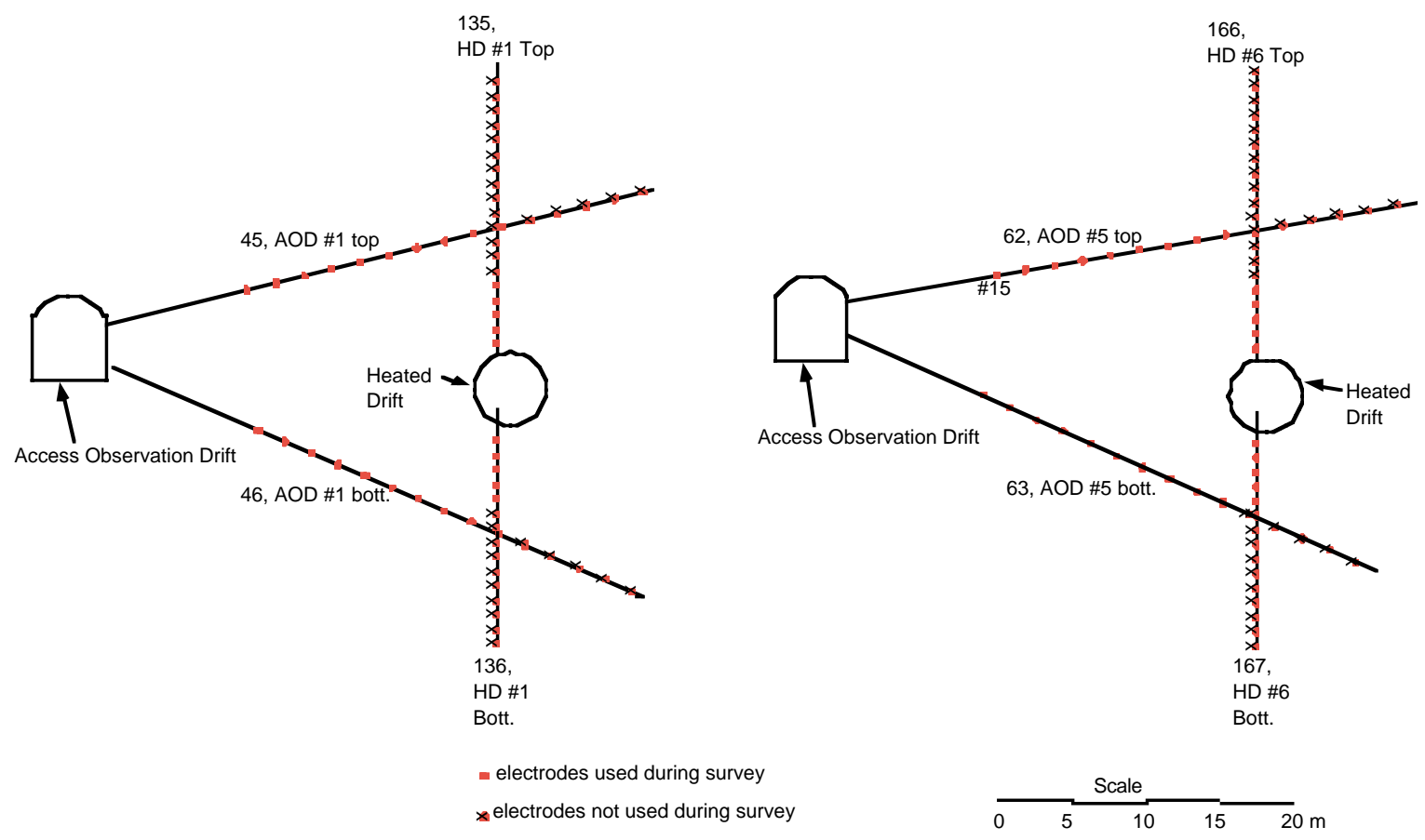

Figure 3 shows the location of the electrodes used for two ERT survey planes orthogonal to the Heated Drift.

\section{Baseline Tomographs:}

Figures 4 and 5 present tomographs of the electrical resistivity distribution prior to heating. The tomographs show regions of relatively low resistivity as blue-colored areas, and regions of relatively high resistivity as red-colored regions. The data processing steps required to produce this tomographs are very similar to the steps taken to process data from the Single Heater Test; a report describing this work can be found under milestone \# SP9215M4.

The data collected between boreholes 135 and 145, and between boreholes 145 and 166 were combined into a single tomography problem. This approach tends to improve the fidelity and resolution of the tomograph around the common borehole (145). The choice 
of combining the 166 - 176, 135 - 145 and 145 - 166 surveys was attempted. Such a combined data set resulted in a very large inversion problem that took very long times to converge; thus this approach was abandoned. Similar comments apply to surveys made below the HD between boreholes 136 and 146, and 146 and 167. The remaining data surveys were processed as individual tomographs.

The tomographs shown in Figure 4 show the resistivity distribution along a cross section parallel to the HD. These tomographs show that the average resistivity is approximately $350 \mathrm{ohm}-\mathrm{m}\left(10^{2.93}\right)$. There also several approximately horizontal regions of relatively low resistivity (blue). The strongest of these features are present below the HD between boreholes 146 and 167 . The root cause of these low-resistivity regions is unknown at the time of writing. Possible reasons for the low resistivity features are: wetter regions in the rockmass, zones with different mineralogy, regions invaded by cement grout, and/or metallic objects in electrical contact with the rock.

The tomographs shown in Figure 5 show the resistivity distribution along two cross sections oriented at right angles to the HD. The left hand image part of the figure shows a resistivity tomograph orthogonal to the HD and about $4 \mathrm{~m}$ away from the bulkhead. This image shows an approximately horizontal low resistivity extending away from the HD. The cause for this feature remains unknown at the time of writing.

The right hand part of Figure 5 shows a resistivity tomograph orthogonal to the HD and about $24 \mathrm{~m}$ away from the bulkhead. This tomograph shows a near vertical region of relatively high resistivity near the center of the image.

Note that for both of the images in Figures 4 and 5, the region that coincides with the HD is modeled as a low resistivity zone due to all the metallic objects (i.e., steel mesh along the walls, rock bolts, cable trays, heater canisters) present along the walls of the HD. 


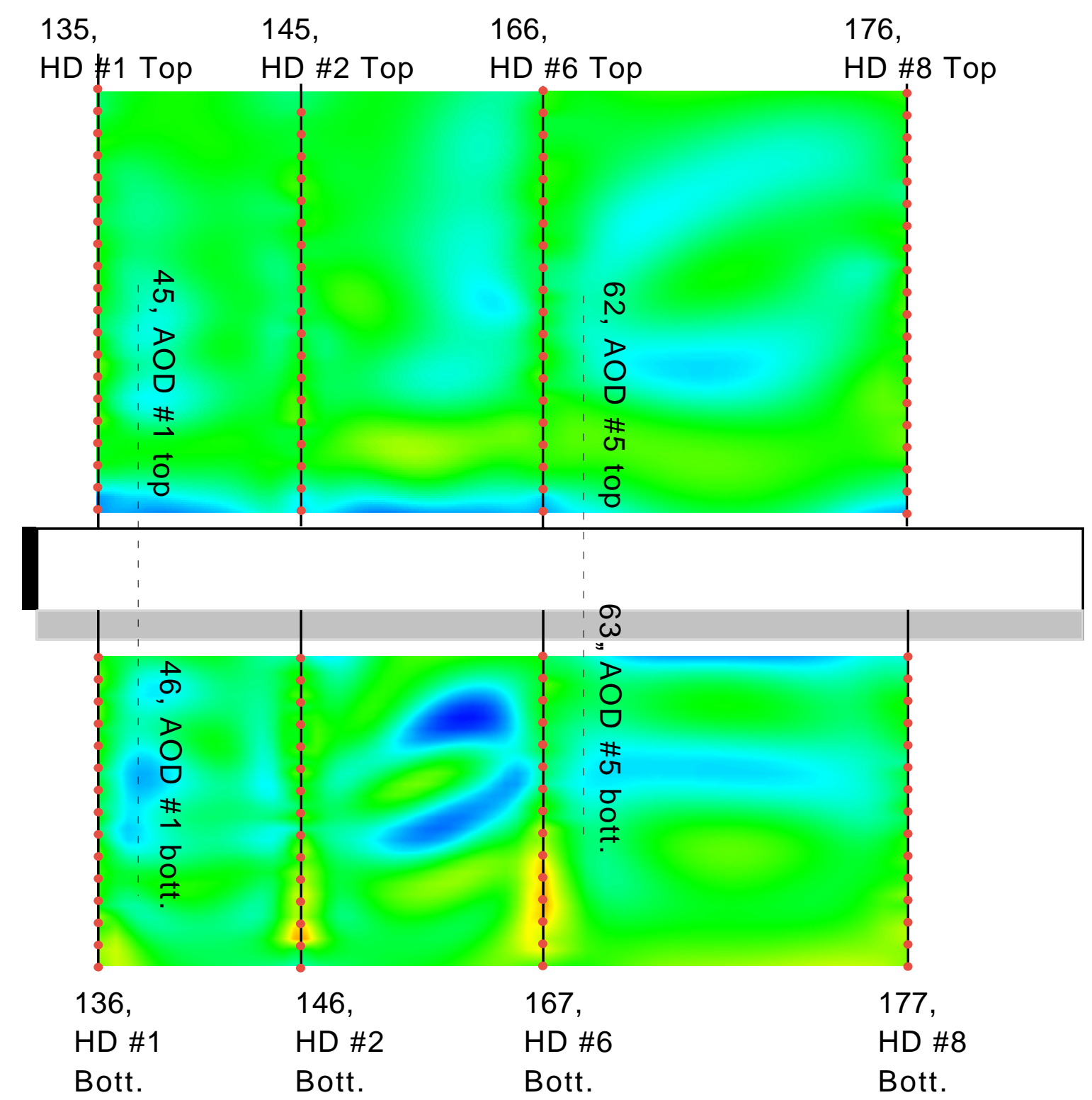

LOG10 Resistivity in Ohm-m

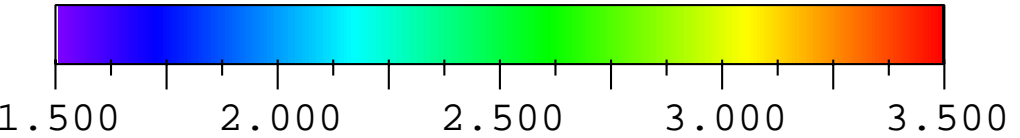

\begin{tabular}{lrrr}
0 & Scale & & \\
\hline & 10 & 15 & $20 \mathrm{~m}$
\end{tabular}

Figure 4. Shows ERT tomographs along a cross-section parallel to the HD. The tomographs present the pre-heating $(11 / 18 / 97)$ electrical resistivity distribution. 


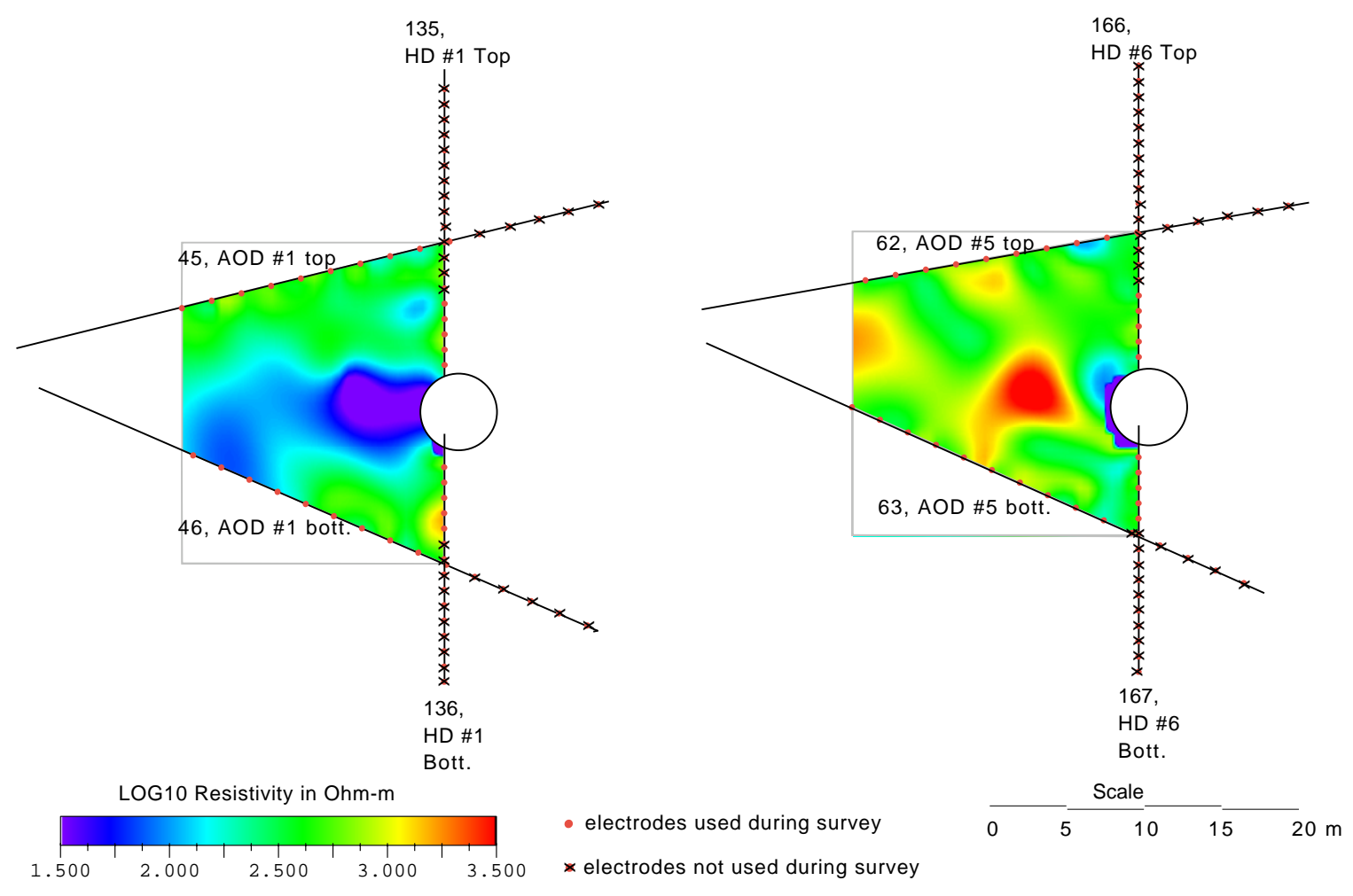




\section{Summary and Conclusions:}

ERT surveys have been conducted around the HD before and after heating started. The surveys are made along vertical planes which are parallel to and orthogonal the HD. During this quarter, three full baseline data sets were collected before heating and one after heating. This report presents tomographic images of absolute electrical resistivity corresponding to the pre-heating conditions. The report also presents the coordinates of the electrodes used for the ERT surveys. The tomographs show that there are several low resistivity zones present. Future reports will show images of electrical resistivity change calculated using data collected before and during the heating episode. The changes to be recovered will then be used in combination with temperature maps of the region to calculate maps of saturation change around the HD.

\section{Acknowledgments:}

This work is performed under the auspices of the U.S. Department of Energy by Lawrence Livermore National Laboratory under contract W-7405-ENG-48. This work is supported by Yucca Mountain Site Characterization Project, LLNL.

\section{References}

LaBrecque, D. J., M. Miletto, W. Daily, A. Ramirez, and E. Owen, 1996, The effects of Noise on Occam's Inversion of Resistivity Tomography Data, Geophysics,, vol. 61, no. 2 , pp. 538-548.

Morelli, G., and D. LaBrecque, 1996, Robust Scheme for ERT Inverse Modeling, Proc. Symposium on the Application of Geophysiscs to Engineering and Environmental Problems, Keystone, April 28 - May 2, 1996. 


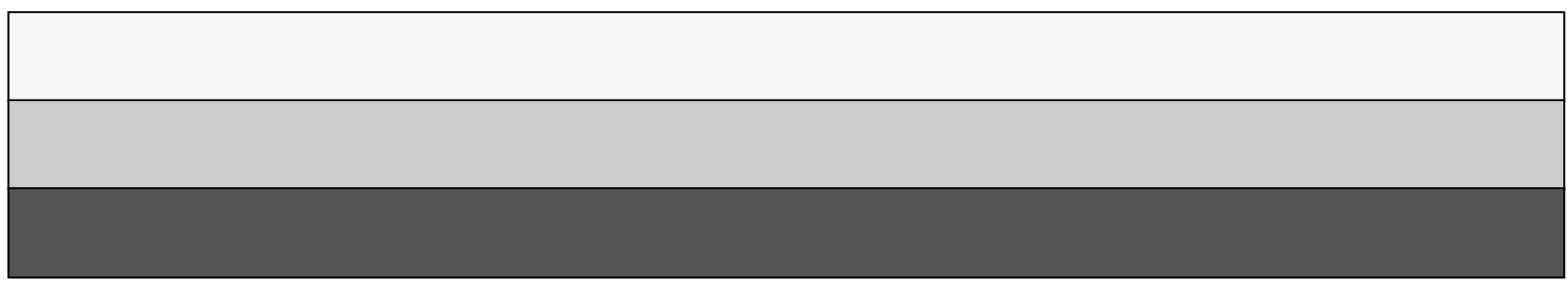

